EGU2020-7037

https://doi.org/10.5194/egusphere-egu2020-7037

EGU General Assembly 2020

(c) Author(s) 2020. This work is distributed under

the Creative Commons Attribution 4.0 License.

\title{
Recent geomorphic destabilization of mountain slopes, a possible link to climate change? Two case studies from Switzerland
}

\author{
Hanne Hendrickx ${ }^{1}$, Reynald Delaloye ${ }^{2}$, Jan Nyssen ${ }^{1}$, and Amaury Frankl ${ }^{1}$ \\ ${ }^{1}$ Ghent University, Geography, Gent, Belgium \\ ${ }^{2}$ Fribourg University, Department of Geosciences, Fribourg, Switzerland
}

Geomorphological destabilisations in high mountain areas are often linked to permafrost degradation and changing precipitation intensities, induced by climate change. Considering the complex interaction between meteorological conditions, geology and topography, two alpine mass movements that took place in 2019 in the canton of Valais (Swiss Alps) were investigated with regard to their possible causes. During three consecutive summers (2017-2019), independent surveys were carried out on a high alpine talus slope at Col du Sanetsch (2100 - $2750 \mathrm{~m}$ a.s.l.) and an unstable rock face at Grosse Grabe, Mattertal (2600 - $2700 \mathrm{~m}$ a.s.l.), using unmanned aerial vehicle (UAV) and terrestrial laser scanning (TLS). The resulting high-resolution topography allows detecting and quantifying small and large geomorphic changes, such as rock tilting, rockfalls, rockslides, erosion and depositions of rock debris by snow avalanche action, debris channel cutting and fill and debris flow deposits. In both study areas, the summer of 2019 was characterized by mass movement events of greater magnitude than the geomorphic activity measured in the summers before.

At Grosse Grabe, the rock face was observed by webcam imagery since 2011, in the background of a rock glacier, which was initially the main object of survey. Isolated rock falls started in January 2017, launching a more accurate survey of the rock face by TLS in July 2017. In the next two summers, the entire unstable part of the rock wall, $70 \mathrm{~m}$ high, had been tilting at an increasing rate $(1$ to $3.3 \mathrm{~cm} / \mathrm{month})$. From mid-July until the end of October 2019, consecutive large rock fall events (up to $>10,000 \mathrm{~m}^{3}$ ) lead to the complete collapse of the monitored rock face $\left(5000 \mathrm{~m}^{2}\right.$ ), with a total volume of more than $60,000 \mathrm{~m}^{3}$. After the collapse of this heavily fractured, south facing rock face, the long-lasting wet rockfall scar indicated the presence of thawing permafrost ice. Beside the geological characteristics, which are favouring the rock wall instability, the consequences of the multi-decennial significant warming of the permafrost is presumably an implicated factor.

On the talus slope $\left(2 \mathrm{~km}^{2}\right)$ that was surveyed at Col du Sanetsch, a large debris flow event (ca. $20,000 \mathrm{~m}^{3}$ spread over multiple debris flow channels) was observed in the evening of 11 August 2019. Most of the mobilized sediments originated from incision of the talus apex area, while only a small part came from intermediate debris storage within rock wall gullies. An analysis of historical aerial photographs shows that the total displaced volume during the 2019 event exceeds each 
historical debris flow event that occurred on the talus slope since 1946.

In contrast to Grosse Grabe, where weather conditions have played no role on the development of the instability, the debris flow event at Col de Sanetsch is linked to an intense prefrontal supercell, causing rainfall intensities between 10 and $25 \mathrm{~mm} / \mathrm{h}$, in some places in less than 15 minutes. As such events are presumed to become more frequent with climate change, more debris flow events of this type can be expected in the future. 